\title{
Multifactorial Contributions to Central Incisor Tooth Morphology and the Presence of Black Triangles: A Case Study
}

\author{
Steven E. Kohane, Katelyn C. Means \\ University of Pittsburgh, School of Dental Medicine
}

\section{Abstract}

Abstract: Dentists are often faced with patient concerns of smile esthetics in addition to oral health and should be equipped to help patients manage both. Black triangle disease, or a lack of interdental papilla, is esthetically displeasing particularly in the central incisor region and has a hoard of etiologies ranging from gum disease to inherited tooth morphologic features. Addressing patients' esthetic concerns must first be met with understanding the causation of the black triangles before treatment can be rendered. Genetic contributions are multifactorial, and this case report provides evidence for a case of a central incisor black triangles without other affected family members.

Background: Black triangles are a prominent feature for those experiencing a lack of interdental papilla between central incisors and may dramatically affect the presentation of a person's smile. The aim of this case report is to convey the importance of managing patients' esthetic chief complaints while addressing the etiology of the esthetic concern.

Case Description: A 24-year-old man presented with concern of his black triangle spaces. The patient does not have gingival recession in the area of interest, and his biological mother and brother do not have black triangle spaces. Pathology is not an issue, but instead inadequate length of the central incisor mesial contact area prevents the interdental papilla from reaching the contact. Esthetics are a concern, but the patient is not interested in irreversible treatment for his healthy tissue.

Practical Implications: Dentists should be aware of the multifactorial contributions to patients' esthetic concerns. Dentists should also be aware that meeting a patient's expectations may require a more complex treatment plan than the patient expected.

Keywords: black triangles; multifactorial inheritance; cosmetic dentistry; esthetics; gingival embrasures; interdental papilla; contact point; tooth morphology; odontometry.

Citation: Kohane SE, et al. (2021) Multifactorial contributions to central incisor tooth morphology and the presence of black triangles: a case study. Dentistry 3000. 1:a001 doi:10.5195/d3000.2021.101 Received: April 30, 2020

Accepted: February 4, 2021

Published: March 10, 2021

Copyright: (C2021 Kohane SE, et al. This is an open access article licensed under a Creative Commons Attribution Work 4.0 United States License.

Email:skohane@pitt.edu

\section{Introduction}

Though dentistry is primarily focused on establishing or restoring patients' oral health, hygiene, and maintenance, dentistry's breadth also covers a wide number of patient esthetic concerns. The smile is a hotspot for quick decision making on appearance, and research shows that esthetic perception-whether by dentists, specialists, or laypeople-of a person's facial type should not be evaluated separately from the smile as it significantly impacts facial type perception [1]. Specifically, the maxillary incisors seem to be the most prominent feature of a smile that affects facial perception, if for no other reason than they are the most anterior and obviously seen in a person's smile. It is no wonder that among patient esthetic smile concerns are straightness, color, and proportional size of teeth, as well as incisal lip coverage.

However, beyond tooth morphology contributing to esthetic concerns of straightness and size, a more overlooked contributor to smile esthetics is the presence or absence of interdental papilla in the mesial 
gingival embrasure of central incisors.

Scientifically, an absence of

interdental papilla in this highly esthetic region has been named a "black triangle." A black triangle is technically defined as a cosmetic deformity due to the loss of interdental papilla [2]. However, a black triangle appearance is not simply a matter of gingival recession and may be caused by many other factors, including bone level, tooth morphology, and contact points [2]. There are great esthetic implications of a "black triangle" being included in such a prominent contributor to facial type perception.

Though the presence of black triangles may be a result of underlying gingival recession or decreased bone height, this is not always the case [2]. Lip length and position also contribute to the visibility of a black triangle - with a high smile line or a thin upper lip, the loss of interdental papilla is more noticeable and contributory to an esthetic judgement [3]. Additionally, it has been noted that black triangles become more prominent with age [4].

Another contributing factor to black triangles is tooth size and shape.

Tooth sizes vary between individuals most noticeably in mesiodistal width and incisocervical length. The ratio of these two measurements have been shown to predict the likelihood of black triangle, and these measurements also contribute to tooth shape or "form" [5]. Three main tooth shapes - square, triangular, and ovoid - are determined by the greatest mesiodistal width of the tooth and whether or not the width is continuous $[2,5]$. The pronounced cervical scallop and incisally located, short contact area of triangular teeth are predisposing to a black triangle appearance $[2,5,6]$. On average and as noted in the case report, the interproximal contact in patients with black triangles is either shorter or located $1 \mathrm{~mm}$ more incisally than patients with adequate interdental papilla [5]. Emergence profile variation - specifically divergent crown form - also contributes to open gingival embrasures, and incisal symmetry should be considered during restorative treatment to maintain esthetics $[7,8,9]$.

Root angulation and divergence, which can be adjusted with orthodontics, also determine crown alignment and presence of interdental bone and papilla. However, prior orthodontic treatment has been associated with longer distances from contact point to crest of the alveolar bone, though shorter distances lead to smaller embrasure areas and consequently a higher chance of sufficient interdental papilla $[6,10,11]$.

Relevant to the scope of this report is the discussion of genetic influence on tooth morphology. Any process which may affect the developing permanent tooth bud can influence the morphology of the incisor, thereby affecting symmetry, contact regions, and interdental papilla spaces. Although patient height and tooth size appear not to correlate [12], tooth organ growth may be modified by nutrition or genetic variation in growth genes. The developing central incisor tooth bud structure is also susceptible to trauma by primary incisor intrusion [13], while the erupted tooth is susceptible to trauma, erosion, attrition, and abrasion. Of note in this report is abrasion, as the interproximal area can be susceptible to abrasion due to improper floss technique.

The objective of this article is to discuss the causation and implication of a less frequently studied dental concern relating to patient aesthetics. Though dentists' primary role in the healthcare field is oral health, as experts of the teeth and mouth it is appropriate to address our patients' chief complaints, even if aesthetic. In order to best address issues of black triangle disease, it is pivotal that we understand the multiple routes of causation before implementing any treatments.

\section{Case Report}

A 24-year-old man presented with concern of a dark space between his maxillary central incisors in February 2020. The patient's chief complaint was stated as "I've got a hole between my teeth and it bothers me. I am of the understanding that it can't be fixed due to my tooth shape, but I also don't think my gingiva is 
recessed. I am often told by close friends that 'There is something between my teeth,' but closer friends know that the dark spot is just my anatomy. I'm sure strangers find it off-putting." The patient was well briefed on the factors which may influence his black triangle appearance, as he had done some research before presentation. However, the patient stated that he wanted to be sure that there was no oral health concern to potentially unveil the cause of his black triangle, and to weigh the pros and cons of any permanent esthetic treatment.

The patient's medical history was significant for ADHD medication for the last 14 years, which he reports causing xerostomia. He reported normal vitals and a BMI of 24 . His dental history was significant for two traditional orthodontic treatments and two Invisalign treatments. He reported brushing twice daily with fluoride and flossing daily, but with improper technique - moving floss straight up and down "without much rubbing of the side of each tooth." Upon clinical examination, the patient's hard tissue charting was

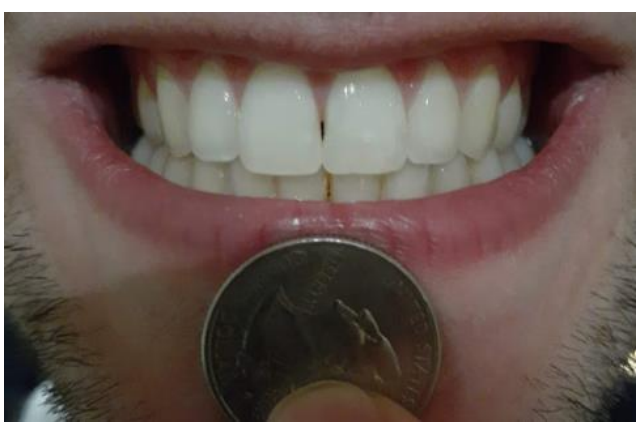

unremarkable with third molar extractions and no caries or restorations. Approximately $2 \mathrm{~mm}$ of gingival recession was noted on the facial of mandibular anterior teeth. The patient admitted to infrequent dental visits, estimating once every two years.

The patient presented with a triangular tooth form (Figure 1a) with tall incisocervical length and short contact length. Maxillary gingival recession was not noted, but an exaggerated scalloped appearance was, which is consistent with triangular tooth form [2]. The patient's black triangle measured $2.1 \mathrm{~mm}$, but both his mother and brother lacked black triangles (Figures $1 a, b)$. The patient's brother's tooth form was triangular and extremely similar to that of the patient, however the brother's contact length was $2.7 \mathrm{~mm}$ longer than that of the patient - a probable cause of the brother's gingival embrasure closure (Table 1). The patient's mother, however, exhibited a square tooth form. As is typical, this square tooth form was accompanied by a longer contact length and a closed gingival

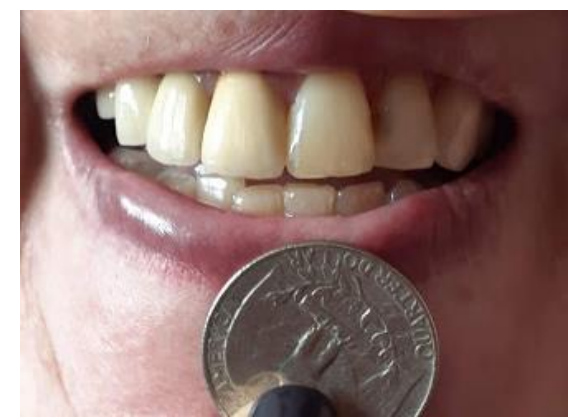

embrasure. The patient's father's information was not available as he was a denture wearer.

To standardize the measurements, images were superimposed on each other using quarter size as a reference. Quarter diameter is $24.26 \mathrm{~mm}$, and figure measurements in $\mathrm{mm}$ (Table 1) were calculated using an on-screen pixel ruler calibrated to the quarter's pixel length. This method of measurement was used to maintain consistent results across locations - the three subjects lived in different regions of the United States, and not all have access to the same calibrated periodontal probe or caliper.

Ultimately, the patient's interdental papilla length was long upon visual inspection. However, it was not long enough to reach the beginning of the contact area, so the patient presented with an unaesthetic black triangle. The patient chose not to pursue treatment for his black triangle because he did not want to subject his healthy tissue to

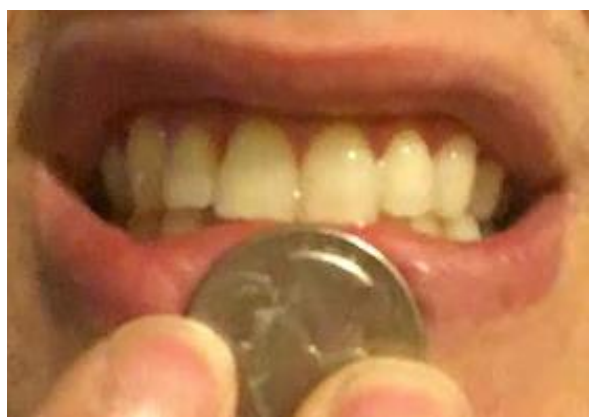

Figure 1. Photos of the patient and family. a) The patient, with open gingival embrasure, b) The patient's biological mother, c) The patient's biological brother 
Table 1. Dimensions of Points of Interest for Black Triangles in millimeters. Only the patient exhibits a black triangle, while his biological mother and brother do not. The most notable measurement is the patient's contact length, which is drastically smaller.

\begin{tabular}{|l|r|r|r|}
\hline Measurements (mm) & Patient & $\begin{array}{l}\text { Patient's } \\
\text { mother }\end{array}$ & \multicolumn{2}{|l|}{$\begin{array}{l}\text { Patient's } \\
\text { brother }\end{array}$} \\
\hline Contact length, incisocervical & 2.5 & 5.3 & 5.2 \\
\hline $\begin{array}{l}\text { Widest mesiodistal (MD) } \\
\text { dimension }\end{array}$ & 8.8 & 9.1 & 8.7 \\
\hline Incisal edge to widest MD point & 3.9 & 1.8 & 1.4 \\
\hline Tip of papilla to widest MD point & 2.3 & 4.6 & 3.5 \\
\hline Black triangle height & 2.1 & & \\
\hline
\end{tabular}

irreversible treatment like composite bonding or veneers, which could lead to secondary decay down the road.

\section{Discussion}

The category where the patient shows greatest divergence from the other subjects is the incisocervical length of the contact point. Adding the length of the black triangle would bring the measurement of incisal edge to tip of interproximal papilla to within $1 \mathrm{~mm}$ of the patient's relatives who have closed gingival embrasures. Indeed, it had been noted that shorter interproximal contacts are associated with open gingival embrasures [5]. Additionally, the patient's crown form was more triangular when compared to those of his relatives and a triangular crown form is associated with black triangles $[5,6]$.
Although some might classify gingival recession as a simple calculation of distance between tip of the papilla to the contact area [10], a pathological process of recession was not thought to be involved, based on the healthy and pointed appearance of the patient's interdental papilla as well as the fact that the papilla extended further incisally than other maxillary anterior papilla. Additionally, if an occlusal radiograph were to be taken of the patient, it would be reasonable to predict adequate bone levels. The patient also did not seem to have a thin gingival biotype, which again indicates that the primary etiology of the patient's black triangle is contact area length.

In respect to treatment, a periodontal surgery would not be advised as the gingival tissue is healthy and there was no clinical recession in the maxillary arch beyond the definition of a measurable distance between the papillary tip to the contact area. Additionally, in the esthetic circumstances of this particular case the teeth being already quite wide and generally large - filling the open gingival embrasure with composite may not have been esthetic either. Other options, including no treatment, must be considered. As in any esthetic case, veneers are an option in restoring the anterior appearance of the smile. However, the patient's esthetics were otherwise ideal, and he opted for no treatment in the case of conservation of healthy tooth structure.

As previously stated, no clear association was found with regards to genetic contribution to body height and tooth size. However, it is possible that the tooth organ's growth may be modified by genetic mechanisms affecting general body growth. Some have identified numerous loci that influence height via genome-wide association analysis [14]. Others have discussed the hormones, paracrine factors, extracellular matrix molecules, and intracellular proteins that affect the growth plates of long bones [15]. With the abundance of genes known to contribute to body growth, it is postulated by the authors that further research will discover a more definitive association to tooth growth and size. The patient is a few inches taller than his relatives, which suggests an explanation to the differences in tooth morphology. 


\section{Conclusions}

Patients often present to the dentist with esthetic concerns including black triangles. Periodontal surgery and grafting are options to restore interdental papilla length in the case of true gingival recession. However, if the main factor contributing to the presence of a black triangle is tooth morphology, then composite bonding and veneers may be an option.

Different "black triangle" cases have specific characteristics which fit more neatly into one category than another for treatment and causation.

\section{References}

1. The Influence of the Smile on the Perceived Facial Type Esthetics. Batwa W. Biomed Res Int. 2018;2018:3562916. eCollection 2018. PMID: 30112381.

2. Black triangle dilemma and its management in esthetic dentistry. Singh VP, Uppoor AS, Nayak DG, Shah D. Dent Res J (Isfahan). 2013 May;10(3):296-301. Review. PubMed PMID: 24019795.

3. Maxillary anterior papilla display during smiling: a clinical study of the interdental smile line. Hochman MN, Chu SJ, Tarnow DP. Int J Periodontics Restorative Dent. 2012 Aug;32(4):375-83. PubMed PMID: 22577642.

4. Clinical studies on the appearance of natural anterior teeth in young and old adults. Hartmann R, Müller F. Gerodontology. 2004 Mar;21(1):10-6. PMID: 15074535.
5. Open gingival embrasures after orthodontic treatment in adults: prevalence and etiology. Kurth JR, Kokich VG. Am J Orthod Dentofacial Orthop. 2001 Aug;120(1):116-23. PMID: 11500652.

6. An analysis on the factors responsible for relative position of interproximal papilla in healthy subjects. Kim JH, Cho YJ, Lee JY, Kim SJ, Choi Jl. Journal of Periodontal \& Implant Science. 2013 Aug 31; 43(4): 160-167. PMID: 24040568.

7. Esthetics: the orthodonticperiodontic restorative connection. Kokich VG. Semin Orthod. 1996 Mar;2(1):21-30. Review. PubMed PMID: 9161280.selct

8. Incidence and size of pretreatment overlap and posttreatment gingival embrasure space between maxillary central incisors. Burke S, Burch JG, Tetz JA. Am J Orthod Dentofacial Orthop. 1994 May;105(5):506-11. PubMed PMID: 8166102.

9. Significance of crown shape in the replacement of a central incisor with a single implant-supported crown. Gobbato L, Paniz G, Mazzocco F, Chierico A, Tsukiyama T, Levi PA Jr, Weisgold AS. Quintessence Int. 2013 May;44(5):407-13. PMID: 23479574.

10. Risk factors associated with open gingival embrasures after orthodontic treatment. An SS, Choi YJ, Kim JY, Chung CJ, Kim KH. Angle Orthod. 2018 May;88(3):267-274. Epub 2018 Jan 16. PMID: 29337634.

11. Factors influencing the presence of interproximal dental papillae between maxillary anterior teeth. Chen MC, Liao YF, Chan CP, Ku YC, Pan WL, Tu YK. J Periodontol. 2010 Feb;81(1):318-24. PMID: 20151812

12. Age-related changes in crown and root length in Sri Lankan Sinhalese. Jayawardena CK, Abesundara AP, Nanayakkara DC, Chandrasekara MS. J Oral Sci. 2009 Dec;51(4):587-92. PubMed PMID: 20032612.

13. Intrusive luxation in primary teeth - Review of literature and report of a case. Gupta M. Saudi Dent J. 2011 Oct;23(4):167-76. Epub 2011 Sep 16. PubMed PMID: 23960512.

14. Genome-wide association analysis identifies 20 loci that influence adult height. Weedon $\mathrm{MN}$, Lango $\mathrm{H}$, Lindgren $\mathrm{CM}$, Wallace $\mathrm{C}$, Evans DM, Mangino $M$, Freathy RM, Perry JR, Stevens S, Hall AS, Samani NJ, Shields B, Prokopenko I, Farrall M, Dominiczak A, Johnson T, Bergmann $S$, Beckmann JS, Vollenweider $P$, Waterworth DM, Mooser V, Palmer $\mathrm{CN}$, Morris AD, Ouwehand WH, Zhao JH, Li S, Loos RJ, Barroso I, Deloukas P, Sandhu MS, Wheeler E, Soranzo N, Inouye $M$, Wareham NJ, Caulfield M, Munroe PB, Hattersley AT, McCarthy MI, Frayling TM. Nat Genet. 2008 May;40(5):575-83. Epub 2008 Apr 6. PubMed PMID: 18391952.

15. Short and tall stature: a new paradigm emerges. Baron $J$, Sävendahl L, De Luca F, Dauber A, Phillip M, Wit JM, Nilsson O. Nat Rev Endocrinol. 2015 Dec;11(12):735-46. Epub 2015 Oct 6. Review. PubMed PMID: 26437621. 